\title{
Inhibition of Steady-State Intestinal Absorption of Long-Chain Triglyceride by Medium-Chain Triglyceride in the Unanesthetized Rat
}

\author{
Susanne Bennett Clark and Peter R. Holt \\ From the Gastrointestinal Research Laboratory, Department of Medicine, \\ St. Luke's Hospital Center, New York 10025
}

A B S T R A C T Maximal steady-state intestinal absorption rates in unanesthetized rats for triolein, a long-chain triglyceride, and for trioctanoin, a medium-chain triglyceride, are known to differ. Both these lipids are hydrolyzed in the intestinal lumen but the products of hydrolysis are metabolized differently by the mucosal cell. Intraduodenal infusion of trioctanoin was found to reduce steady-state triolein absorption. Luminal lipolysis was shown not to be rate-controlling. High rates of trioctanoin infusion significantly lowered the $\mathrm{pH}$ of the luminal aqueous phase and altered the partition of oleic acid between aqueous and oil phases. Two possible mechanisms for the inhibition of triolein uptake are considered. In the intestinal lumen medium chain lipids might have lowered the activity of oleic acid monomers in the aqueous phase and reduced passive diffusion into mucosal cells. Alternatively, competition between long and medium chain fatty acids for some common receptor during transport into the intestinal mucosal cell may have occurred.

Despite significant inhibition of triolein absorption by high levels of trioctanoin, the maximum number of calories absorbed from mixtures of triglycerides exceeded the maxima from either glyceride alone. The optimum proportion of triolein to trioctanoin in lipid infusion mixtures was about $3: 4$ by weight and the optimum dosages about half maximal for each triglyceride, which represented a caloric intake of $4 \mathrm{kcal} / \mathrm{rat}$ per 2 $\mathrm{hr}$. The absorption coefficient for this lipid mixture was about $90 \%$. It is suggested that in patients who have a limited intestinal absorptive capacity dietary fat intake might be doubled with a caloric supplement of mediumchain triglycerides without increase in steatorrhea of long-chain fat.

This work was published in part as an abstract (1).

Received for publication 29 April 1969 and in revised form 24 June 1969.

\section{INTRODUCTION}

The rate of intestinal absorption of a fatty meal eaten under normal conditions is limited by the rate of gastric emptying. When this controlling mechanism is bypassed in unanesthetized rats and fat emulsions are continuously infused under steady-state conditions through indwelling cannulae directly into the duodenum, a further rate-controlling step located in the small intestine can be demonstrated (2). Definite steady-state absorption maxima have been established for several triglycerides studied under these conditions. The maximum absorption rates for different fats vary widely, with shorter chain length triglycerides much more rapidly absorbed (3). It was the purpose of the present investigation to attempt to characterize further the rate-controlling step in the absorption of triglycerides of different chain length.

During intestinal absorption in vivo, long and medium chain fats follow some common and some divergent paths. Both are hydrolyzed to fatty acids and glycerides by pancreatic lipase in the intestinal lumen $(4,5)$, and the products of lipolysis of both triglycerides probably enter the mucosal cell membrane from an aqueous luminal phase. The absorption of medium-chain fat differs from that of long-chain fat in the lumen, where mediumchain fatty acids do not require bile salts for adequate solubilization (6), and inside the mucosal cell, where they are not reesterified (7) but pass rapidly into the portal blood stream. One approach to the understanding of the rate-controlling steps in fat absorption was to study the steady-state absorption of a typical long-chain triglyceride, triolein (LCT), in the presence of graded amounts of a typical medium-chain triglyceride, trioctanoin (MCT). A reduction in the absorption rate of triolein in the presence of trioctanoin under these conditions would imply competition in some common region traversed by both lipids during absorption. Such a re- 


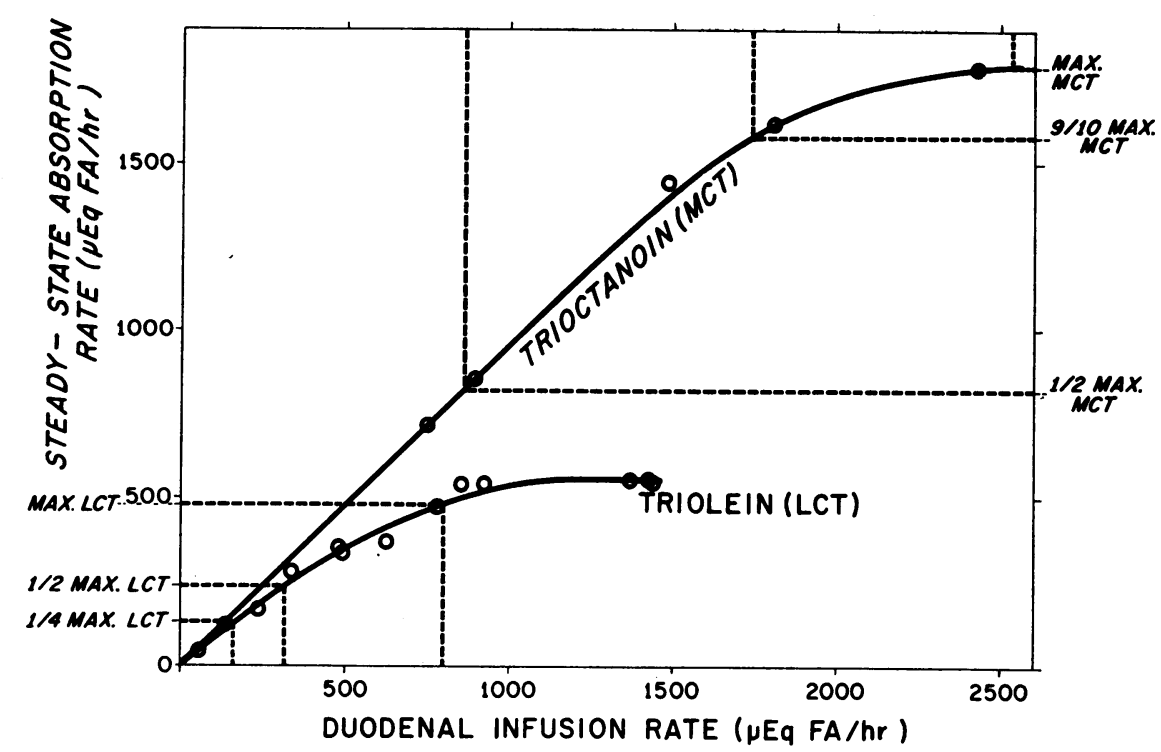

FIGURE 1 Triolein and trioctanoin steady-state absorption rates. Curves show relation between intraduodenal lipid infusion rates and absorption rates for the pure triglyceride emulsions. 0 , mean of two-four animals in a group. Absorption rates calculated from difference between total lipid infused in $2 \mathrm{hr}$ and amount recovered after $2 \mathrm{hr}$ from gastrointestinal tract. FA, fatty acids. Dotted lines indicate levels of each triglyceride infused in mixed emulsions.

sult might suggest that fatty acids do not enter the intestinal mucosa entirely by free diffusion.

\section{METHODS}

\section{Materials and infusion mixtures}

Glycerol trioleate-1 $1{ }^{14} \mathrm{C}$, glycerol trioleate-9, $10-{ }^{3} \mathrm{H}$, and glycerol trioctanoate-1 $-{ }^{14} \mathrm{C}$ were obtained from Nuclear Chicago, Des Plaines, Ill., and New England Nuclear Corp., Boston, Mass. By thin-layer chromatography, more than $98 \%$ of each isotope proved to be triglyceride.

Commercial triolein ( $\mathrm{K} \& \mathrm{~K}$ Laboratories, Inc., Plainview, N. Y.) was washed repeatedly with ethanol to remove the free fatty acid present. After separation of the two phases, residual ethanol in the oil fraction was removed under reduced pressure at room temperature. The final product, when titrated with alcoholic alkali, contained more than $98 \%$ triglyceride. Component fatty acids measured by gasliquid chromatography were 14:0 (3.5\%), 14:1 (1.9\%), $16: 0(1.2 \%), 16: 1$ (14.0\%), and 18:1 (79.4\%). Trioctanoin, certified reagent (Eastman Organic Chemicals, Rochester, N. Y.) contained more than 99\% triglyceride. Lecithin, vegetable origin, and dextrose, certified reagent, were obtained from Fisher Scientific Company, Pittsburgh, $\mathrm{Pa}$., and Pluronic F-68 was obtained from the Upjohn Company, Kalamazoo, Mich.

Stock emulsions. Triolein, approximately $22 \% \mathrm{w} / \mathrm{v}$-triolein, $60 \mathrm{ml}$; lecithin, $6.0 \mathrm{~g}$; Pluronic F-68, $1.5 \mathrm{~g}$; dextrose, $10.4 \mathrm{~g}$; and water, to make $250 \mathrm{ml}$. Final concentration was $720 \mu \mathrm{Eq}$ of fatty acid/ml of emulsion. Trioctanoin, approximately $25 \% \mathrm{w} / \mathrm{v}$-trioctanoin, $110 \mathrm{ml}$; lecithin, $9.6 \mathrm{~g}$; Pluronic F-68, $2.4 \mathrm{~g}$; dextrose, $16.6 \mathrm{~g}$; and water, to make $400 \mathrm{ml}$. Final concentration was $1660 \mu \mathrm{Eq}$ of fatty acid/ml of emulsion.
After addition of the appropriate isotopes, the mixtures were sonicated until homogeneous and then stored in a refrigerator. Although no significant layering occurred during several weeks of cold storage, the emulsions were routinely resonicated shortly before use. The specific activities (S.A.) of the stock emulsions were chosen from preliminary results to yield the optimum ${ }^{3} \mathrm{H}:{ }^{14} \mathrm{C}$ ratio of not more than $5: 1$ in luminal washings from all subsequent experiments (see counting methods). The most suitable S.A.'s were: triolein-9,10- ${ }^{8} \mathrm{H}$ emulsion-500 $\mu \mathrm{c} / 100 \mathrm{ml} \simeq$ $500 \mathrm{cpm} / \mu \mathrm{Eq}$ oleic acid, and trioctanoin- $1-{ }^{14} \mathrm{C}$ emulsion-1 $\mathrm{mc} /$ $100 \mathrm{ml} \simeq 1500 \mathrm{cpm} / \mu \mathrm{Eq}$ of octanoic acid at optimal counter settings.

The quantities of triolein- ${ }^{8} \mathrm{H}$ and trioctanoin- ${ }^{14} \mathrm{C}$ stock emulsions used in mixed infusions were chosen so as to give widely differing absorption rates for each lipid after initial experiments had established the relation between infusion and absorption rates for the pure triglycerides (see Fig. 1). Sixteen infusion mixtures were prepared using all combinations of both stock emulsions (Table I).

TABLE I

Proportionate Volumes of Triolein and Trioctanoin Stock Emulsions Used in Mixed Lipid Infusions

\begin{tabular}{|c|c|c|c|c|}
\hline $\begin{array}{l}\text { Triolein-9,10-i } \\
\quad(720 \mu \mathrm{Eq} \mathrm{FA} / \mathrm{ml}), \mathrm{ml}\end{array}$ & 0 & 2 & 4 & 10 \\
\hline $\begin{array}{l}\text { Trioctanoin-1-14 } \mathrm{C} \\
\quad(1660 \mu \mathrm{Eq} \mathrm{FA} / \mathrm{ml}), \mathrm{ml}\end{array}$ & 0 & 5 & 10 & 15 \\
\hline
\end{tabular}

Volumes less than $20 \mathrm{ml}$ were made up to $20 \mathrm{ml}$ with isotonic glucose solution and sonicated briefly to ensure adequate mixing. The final mixture (triolein $10 \mathrm{ml}$ : trioctanoin $15 \mathrm{ml}$ ) was infused at $2.5 \mathrm{ml} / \mathrm{hr}$ and all other mixtures at $2.0 \mathrm{ml} / \mathrm{hr}$. 
In addition to doubly labeled emulsions, triolein $-1-{ }^{14} \mathrm{C}$ was infused in some selected experiments with nonradioactive trioctanoin.

\section{Animal methods and sample collection}

Male rats of Wistar strain, weight range $230-260 \mathrm{~g}$, were prepared with indwelling duodenal cannulae. Surgical procedures and postoperative maintenance have been described previously $(2,3)$. The restrained animals were allowed tap water but no food for $48 \mathrm{hr}$ after surgery. Triglyceride emulsions were then infused intraduodenally at a constant rate of $2 \mathrm{ml} / \mathrm{hr}$, generally for $2 \mathrm{hr}$. Two methods were used for collection and analysis of gastrointestinal contents.

Estimation of absorption from the gastrointestinal lumen. With the animal anesthetized, the stomach, small intestine, cecum, and sometimes colon were separately tied off and washed with $25,50,25$, and $25 \mathrm{ml}$ respectively of isotonic $\mathrm{NaF}$-glycine buffer ( $\mathrm{pH} 3.5$ ). The washings were homogenized with a syringe and triplicate $1 \mathrm{ml}$ aliquots of each were placed in counting vials. Other aliquots were extracted with 5 volumes of chloroform-methanol $(2: 1, \mathrm{v} / \mathrm{v})$ for thin-layer chromatography of lipid components in the chloroform phase.

Micellar and oil phases. The contents of the small intestine were emptied into a small calibrated centrifuge tube, heated at $70^{\circ} \mathrm{C}$ for $10 \mathrm{~min}$ to inactivate pancreatic lipase, and spun for $5 \mathrm{hr}$ at $35^{\circ} \mathrm{C}$ and $100,000 \mathrm{~g}$ in a Spinco high speed centrifuge fitted with a 50.1 rotor. The volumes of oil, interface, aqueous phase, and sediment were measured, and when required, the $\mathrm{pH}$ of the aqueous phase was also measured using a $\mathrm{pH}$ meter. Aliquots of oil phases were diluted with chloroform before further analyses by thin layer chromatography. Aliquots of the aqueous phases were usually spotted directly on thin layer plates without prior extraction.

\section{Analytical methods}

Thin-layer chromatography (TLC). Only samples from animals infused with ${ }^{14} \mathrm{C}$-labeled lipids were chromatographed.

Chloroform extracts (buffered intestinal washings), samples diluted with chloroform (oil phases), or aqueous aliquots taken directly from centrifuge tubes (aqueous phases) were streaked across boric acid/silica gel plates and devel-

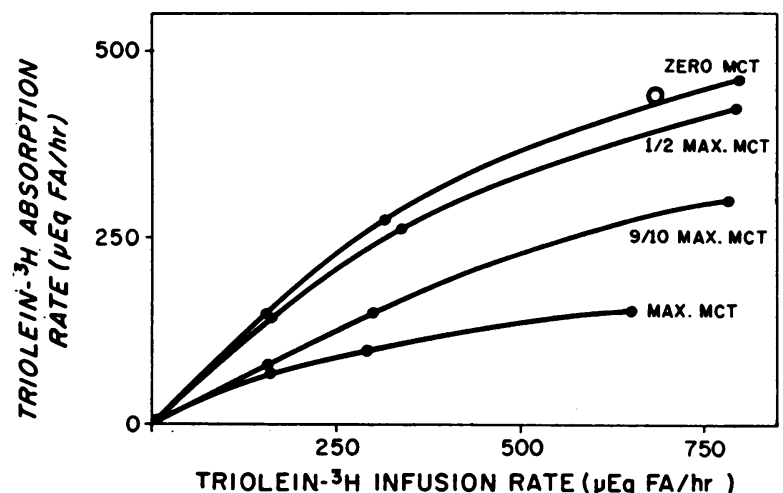

FIGURE 2 Effect of trioctanoin-1-14 C infusion on steady-state absorption of triolein-9,10- ${ }^{8} \mathrm{H}$. - , mean triolein absorption rates. Groups contained two-six animals. $O$, triolein alone with same emulsifier concentration as groups receiving $\frac{9}{10}$ maximal MCT; mean of three animals.

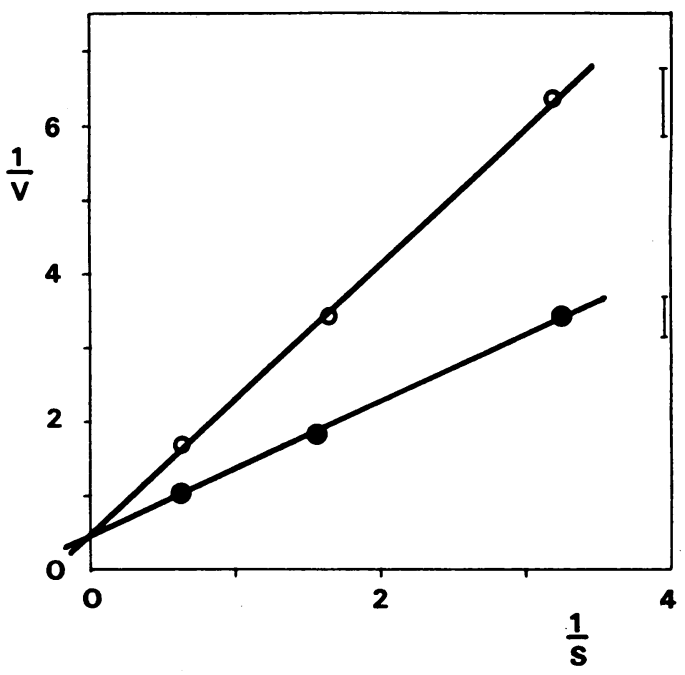

FIGURE 3 Competition between trioctanoin and triolein steady-state absorption in vivo. $\mathrm{V}$, triolein absorption rat? $(\mathrm{mEq}$ oleic acid/2 $\mathrm{hr}$ ). $\mathrm{S}$, triolein infusion rate $(\mathrm{mEq}$ oleic $\mathrm{acid} / 2 \mathrm{hr}$ ). ๑, no MCT; $\mathrm{O}$, 竞 maximal MCT; $\mathrm{SE}$ of least squares line is shown by vertical lines.

oped in $4 \%$ acetone in chloroform (8). Areas containing the origin, 1- and 2-monoglycerides, fatty acids, diglycerides, and triglycerides, were marked according to a sprayed strip containing lipid standards and scraped into separate counting vials.

Counting methods. All samples were counted in $15 \mathrm{ml}$ of Bray's solution (9). Samples containing only ${ }^{14} \mathrm{C}$ were counted at $1100 \mathrm{v}$, with internal standards where necessary to correct for quenching (TLC fractions, aqueous and diluted oil phases after high speed centrifugation). Samples of luminal washings containing only ${ }^{8} \mathrm{H}$ were "spiked" with appropriate amounts of toluene- ${ }^{14} \mathrm{C} .{ }^{8} \mathrm{H}$ and ${ }^{14} \mathrm{C}$ were counted simultaneously at $1400 \mathrm{v}$ in the two channel liquid scintillation counter (Packard Tricarb Model $314 \mathrm{E}$ ) using an adaptation of the method of Bush (10). Calculated recoveries of ${ }^{8} \mathrm{H}$ and ${ }^{14} \mathrm{C}$ from bottles containing standard quantities of both isotopes and intestinal washings from several rats were between 90 and $105 \%$ provided that not more than $50 \%$ of the ${ }^{11} \mathrm{C}$ was counted with ${ }^{8} \mathrm{H}$ in channel one and the ratio of unquenched ${ }^{8} \mathrm{H}$ to ${ }^{14} \mathrm{C}$ was not more than $5: 1$. Statistical analysis of luminal recoveries of triolein $-{ }^{8} \mathrm{H}$ and trioctanoin-14 $\mathrm{C}$ measured simultaneously after infusions of mixed labeled emulsions established that, under the conditions chosen, corrected ${ }^{3} \mathrm{H}$ level were unaffected by levels of ${ }^{14} \mathrm{C}$ in the same counting vials.

\section{Calculations}

Absorption rate. Net uptake of labeled lipid from the gastrointestinal lumen was calculated from the difference between the amount of each lipid infused and the amount recovered from the gastrointestinal tract after the infusion period.

Aqueous concentration of unionized oleic acid. This was calculated from the total oleic acid concentration obtained from thin layer chromatography of the luminal aqueous phase and the $\mathrm{pH}$ of the aqueous phase. The $\mathrm{pKa}$ of oleic acid in bile salt solution, 6.6, (11) was used since data on the $\mathrm{pKa}$ of oleic acid in mixed micellar lipid solu- 
TABLE II

Luminal Lipolysis of Triolein and Trioctanoin During Maximal Steady-State Triolein Intraduodenal Infusion

\begin{tabular}{|c|c|c|c|c|c|}
\hline & & Zero $\mathrm{MCT}$ & 1/2 Max MCT & 9/10 Max MCT & $\operatorname{Max}$ MCT \\
\hline Infused in $2 \mathrm{hr}$ & $\begin{array}{l}\text { LCT } \\
\text { MCT }\end{array}$ & $\begin{array}{r}1609 \\
0\end{array}$ & $\begin{array}{l}1586 \\
1687\end{array}$ & $\begin{array}{l}1568 \\
3839\end{array}$ & $\begin{array}{l}1292 \\
4632\end{array}$ \\
\hline Lipid recovered from lumen & $\begin{array}{l}\mathrm{LC} \\
\mathrm{MC}\end{array}$ & $\begin{array}{r}665 \\
0\end{array}$ & $\begin{array}{l}742 \\
231\end{array}$ & $\begin{array}{l}963 \\
607\end{array}$ & $\begin{array}{r}990 \\
1334\end{array}$ \\
\hline Lipid absorbed in $2 \mathrm{hr}$ & $\begin{array}{l}\mathrm{LC} \\
\mathrm{MC}\end{array}$ & $\begin{array}{r}944 \\
0\end{array}$ & $\begin{array}{r}844 \\
1456\end{array}$ & $\begin{array}{r}604 \\
3232\end{array}$ & $\begin{array}{r}302 \\
3298\end{array}$ \\
\hline FFA recovered from lumen & $\begin{array}{l}\mathrm{LC} \% \text { as } \mathrm{FA} \\
\mathrm{MC} \% \text { as } \mathrm{FA}\end{array}$ & $\begin{array}{c}53^{*} \\
0\end{array}$ & ${ }^{61^{*}}-$ not & $\begin{array}{r}56^{*} \\
\text { asured- }\end{array}$ & $\begin{array}{l}60^{*} \\
63^{*}\end{array}$ \\
\hline Absorbed as FFA in $2 \mathrm{hr}$ & $\begin{array}{l}\text { LC‡ } \\
\text { MC§ }\end{array}$ & $\begin{array}{r}708 \\
0\end{array}$ & $\begin{array}{r}632 \\
1456\end{array}$ & $\begin{array}{r}453 \\
3232\end{array}$ & $\begin{array}{r}226 \\
3298\end{array}$ \\
\hline Total FA released from TG in $2 \mathrm{hr}$ & $\begin{array}{l}\mathrm{LC} \\
\mathrm{MC} \\
\mathrm{LC} \text { and MC }\end{array}$ & $\begin{array}{r}1058 \\
0 \\
1058\end{array}$ & $\begin{array}{l}1081 \\
1456-1687 \| \\
2537-276811\end{array}$ & $\begin{array}{l}933 \\
3232-383911 \\
4225-4832\end{array}$ & $\begin{array}{r}815 \\
4139 \\
4954\end{array}$ \\
\hline
\end{tabular}

All numbers are group means (2-6 animals), expressed in $\mu \mathrm{Eq}$ of fatty acid unless otherwise indicated.

* Mean of 2 animals; range $2 \%$ or less.

$\ddagger$ Assume $75 \%$ of triolein absorbed as fatty acid.

$\$$ Assume $100 \%$ of trioctanoin absorbed as fatty acid.

"Lower limit assumes none of luminal medium chain fat recovered was fatty acid. Upper limit assumes all of luminal medium chain fat recovered was fatty acid.

tions is not yet available. The term "aqueous" used throughout includes both micellar and monomeric fatty acid.

Statistical analyses of variance. These were carried out as outlined by Winer (12).

\section{RESULTS}

At the highest triolein infusion rate, the absorption rate of triolein alone was $472 \mu \mathrm{Eq}$ of oleic acid/hr. When trioctanoin was included in the infusion mixture, both the luminal recovery of triolein and the absorption rate were significantly altered at all levels of triolein infusion $(P<0.001$ for each) (Fig. 2). The magnitude of the effect depended on the amount of trioctanoin infused $(P<0.01)$. At the lowest trioctanoin infusion rate $(1 / 2$ maximal) the reduction of triolein absorption was quite small, but as the amount of trioctanoin infused was increased, striking inhibition of triolein absorption was observed. During maximal infusion of triolein (780 $\mu \mathrm{Eq}$ of fatty acid/hr) the addition of trioctanoin (9/10 maximal) decreased intestinal triolein absorption from 472 to $302 \mu \mathrm{Eq} / \mathrm{hr}$. At maximal trioctanoin infusion the inhibition of triolein absorption reached $68 \%$ (mean maximal triolein absorption rate $151 \mu \mathrm{Eq}$ of fatty acid/ hr).

To ensure that the slower $2 \mathrm{hr}$ triolein absorption rate observed during simultaneous MCT infusion was not due merely to a delay in achievement of a steady state of absorption, selected groups of animals were infused with triglyceride mixtures for $3 \mathrm{hr}$ periods ( $1 / 4$ maximal and maximal triolein, each with maximal trioctanoin). There was no increase in the hourly triolein absorption rates during the prolonged infusions.

Since the animal preparation used in the present experiments produced a steady state of intestinal ab-

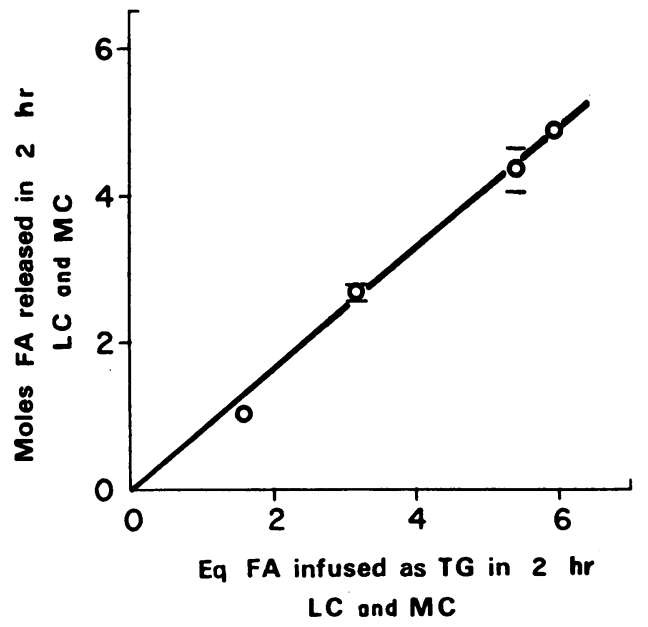

FIgURE 4 Total luminal lipolysis of long-chain (LC) and medium-chain (MC) triglycerides during steady-state infusion. $O$, unesterified oleic and octanoic acids $53-63 \%$ of luminal long and medium chain lipids (see Table II). Where not measured, MCFA assumed to be $60 \%$ of luminal MC lipids. Horizontal bars show maximum possible range of fatty acid released during experimental period (see text and Table II). 
sorption, it seemed feasible to apply Michaelis-Menten kinetics. Lineweaver-Burk plots were made in which the triolein absorption rate corresponded to the reaction velocity and the infusion rate to the substrate concentration (Fig. 3). The lines obtained for triolein alone and for triolein with $9 / 10$ maximal trioctanoin (which produced about $35 \%$ reduction in triolein absorption) intersect on the $1 / \mathrm{V}$ axis. Within the limitations of a kinetic analysis applied to the present studies, the data therefore suggest competition between LCT and MCT absorption for a restricted pathway. Competition for a common step during the absorption of a long-chain triglyceride, triolein, and a medium-chain triglyceride, trioctanoin, might have occurred in the lumen during pancreatic lipolysis, during passage through the mucosal brush border membrane, or intracellularly in some manner not yet described. Medium-chain lipids also might have altered the partition of oleic acid between micellar and oil phases in the lumen or the chemical activity of oleic acid in the aqueous monomer phase.

Intraluminal lipolysis of triolein. The lipid composition of intraluminal contents at the end of the infusion period was analyzed and the total amount of fatty acid released during the $2 \mathrm{hr}$ of the experiment was calculated. Computations were based on the data of Mattson and Volpenhein (13) which implied that $75 \%$ of triolein fed to rats was absorbed as fatty acid. It was assumed that trioctanoin already absorbed had entered the mucosa as free fatty acid (6). The results of such calculations in animals receiving maximal infusions of triolein with differing amounts of trioctanoin appear in Table II which shows that approximately $65 \%$ of the

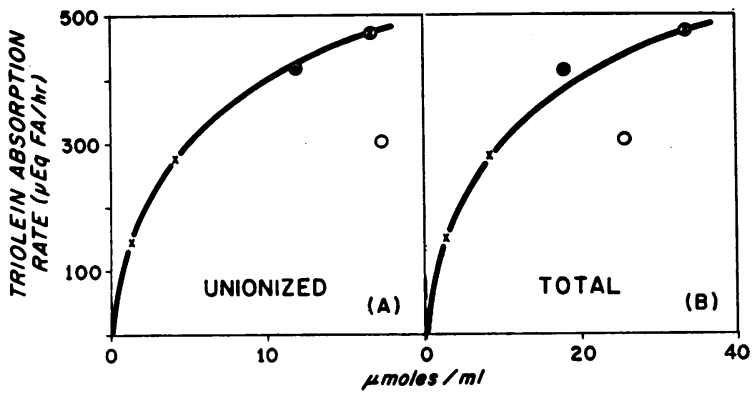

STEADY STATE MICELLAR OLEIC ACID CONCENTRATION ( $\mu$ moles $/ \mathrm{ml}$ )

FIgURE 5 Relation between aqueous oleic acid concentration and triolein absorption rate.

\begin{tabular}{rlc}
\hline & \multicolumn{1}{c}{ Infusions } & $\begin{array}{c}\text { Mean } \\
\text { aqueous } \mathrm{pH}\end{array}$ \\
\hline $\mathrm{X} \otimes$ & $\begin{array}{l}\text { Triolein alone, same animals as in Fig. 2 } \\
\odot\end{array}$ & 6.6 \\
$\bigcirc$ & $\begin{array}{l}\text { Maximal triolein in 0.1 M phosphoric acid } \\
\bigcirc\end{array}$ & 6.2 \\
Maximal triolein plus 品 maximal tri- & 5.9 \\
$\mathrm{X} \bigcirc \odot$ & $\begin{array}{l}\text { octanoin, same animals as in Fig. 2 } \\
\text { mately maximal) }\end{array}$ \\
\hline
\end{tabular}

triolein infused must have been hydrolyzed during the experimental period irrespective of the level of simultaneous trioctanoin infusion. The absorption of triolein was nevertheless considerably reduced in the presence of trioctanoin while the luminal recovery of unesterified oleic acid increased greatly.

When the total fatty acid (LC and MC) released into the intestinal lumen in $2 \mathrm{hr}$ in all experimental groups was plotted against the total lipid infused (Fig. 4), a linear relation was obtained. Even the highest levels of triglyceride infusion reached under the present conditions were therefore well below the capacity of the luminal lipase to split triglyceride. These data indicate that competition between trioctanoin and triolein for pancreatic lipolysis was not responsible for the inhibition of triolein absorption.

Distribution of oleic acid between aqueous and oil phases. The partition of a fatty acid between an oil phase and an aqueous phase is influenced both by the volume of each phase and by the $\mathrm{pH}$ of the aqueous phase which controls the degree of ionization of the fatty acid. In rats which received triolein alone, the relative volumes of the oil and aqueous phases and the $\mathrm{pH}$ of the aqueous phases were similar at all infusion levels studied. The oil phase comprised less than 3\% of the luminal contents, and the luminal $\mathrm{pH}$ was close to the $\mathrm{pKa}$ of oleic acid in bile salt solution above the critical micellar concentration (6.6-6.7). If absorption takes place from the monomeric aqueous phase and not as whole micelles, the steady-state intestinal absorp.ion rate should be directly related to the aqueous monomer concentration of the fatty acid. Unfortunately, no satisfactory methods are available for measurement of monomer concentrations in micellar solutions. However, in the present experiments the relation between the triolein absorption rate and the total aqueous oleic acid concentration, which assumes that all the absorbed lipid was taken up as the fatty acid, was nonlinear and exhibited saturation properties (Fig. 5 B). Saturation was also shown when the unionized form of oleic acid was assumed to be the diffusing entity (Fig. $5 \mathrm{~A}$ ). In either case, correction for the amount of triolein likely to have been absorbed as monoglyceride would merely have increased the deviation from a straight line.

When trioctanoin was added in large amounts to the triolein infusions, the concentrations of oleic acid in luminal oil and aqueous phases and the $\mathrm{pH}$ of the aqueous phase were greatly altered. Moreover, the volume of the oil phase of intestinal contents was increased during high rates of trioctanoin infusion from less than $3 \%$ of the luminal contents in two animals given maximal triolein alone to $10 \%$ in an animal which received maximal triolein with maximal trioctanoin. The long-chain fatty acid content of both phases varied with the 
amount of MCT infused together with maximal triolein infusions. The aqueous concentration of oleic acid was reduced from 35 and $36 \mu \mathrm{moles} / \mathrm{ml}$ in two animals without MCT to $23 \mu \mathrm{moles} / \mathrm{ml}$ in two animals with $9 / 10$ maximal MCT infusion. The mean $\mathrm{pH}$ of the aqueous phase from four animals in each group was lowered from 6.7 to $5.9(P<0.005)$. Either the expanded oil phase or the lower luminal $\mathrm{pH}$, which resulted from high concentrations of octanoic acid released during rapid hydrolysis of trioctanoin, might have reduced the aqueous concentration of long-chain fatty acid. To determine which effect was predominant, the distribution of oleic acid between oil and aqueous phases in mixtures containing long and medium chain lipids, bile salts, and mineral oil was investigated in vitro. The quantities of lipid chosen for these experiments simulated intestinal contents at maximal triolein infusion rates. At equilibrium, the aqueous concentration of oleic acid partitioned between a micellar phase of buffered sodium taurocholate-monoolein and an oil phase of triolein-mineral oil was reduced equally by either a $30 \%$ increase in the oil volume at a constant $\mathrm{pH}$ of 6.7 or a reduction in $\mathrm{pH}$ from 6.7 to 6.3 while the oil volume was kept constant.

In order to exclude the possibility that the low luminal $\mathrm{pH}$ was itself responsible for the significant reduction of LCT absorption rate produced by MCT, a group of three animals was infused with maximal triolein alone emulsified in $0.1 \mathrm{M}$ phosphoric acid ( $\mathrm{pH}$ of infusion mixture $=1.5$ ). This infusion lowered the luminal $\mathrm{pH}$ to 6.2 after $2 \mathrm{hr}$. When the triolein absorption rate and the aqueous concentration of oleic acid present at the end of the acid lipid infusion were estimated as before, the point relating these values corresponded with both curves obtained with normal luminal $\mathrm{pH}$, when the abscissa was either the unionized or the total aqueous oleic acid concentration (see Fig. 5). Low luminal $\mathrm{pH}$ did not alter the form of the relations between aqueous unionized or total oleic acid concentration and triolein absorptioin rate, which both remained nonlinear. On the other hand, in animals receiving high levels of LCT with 9/10 maximal MCT whose luminal $\mathrm{pH}$ was also reduced, the triolein absorption rate was much less than would have been predicted either from the total aqueous or aqueous unionized oleic acid concentrations (see Fig. 5).

One additional group of animals was infused with maximal triolein-1 ${ }^{14} \mathrm{C}$ plus the extra emulsifiers normally infused into animals receiving 9/10 maximal MCT but no trioctanoin was given. As shown in Fig. 2 , no decrease in triolein absorption was observed.

Effect of triolein- ${ }^{3} \mathrm{H}$ infusion on trioctanoin $-{ }^{14} \mathrm{C} a b$ sorption. In contrast to the inhibition of LCT absorption by MCT, luminal recoveries of unabsorbed trioctanoin and trioctanoin absorption rates were unaltered by simultaneous triolein infusion at all levels of trioctanoin infusion studied $(P>0.8)$ (Fig. 6). The concentration of octanoic acid in the aqueous phase during maximal MCT absorption with and without LCT varied between 160 and $270 \mu$ moles $/ \mathrm{ml}$ but no correlation with the level of LCT infusion was found.

Total fat intake during infusion of mixed emulsions. In Fig. 7 the results are summarized in the form of a balance sheet showing the total amounts of each fat and the corresponding calories absorbed and not absorbed in

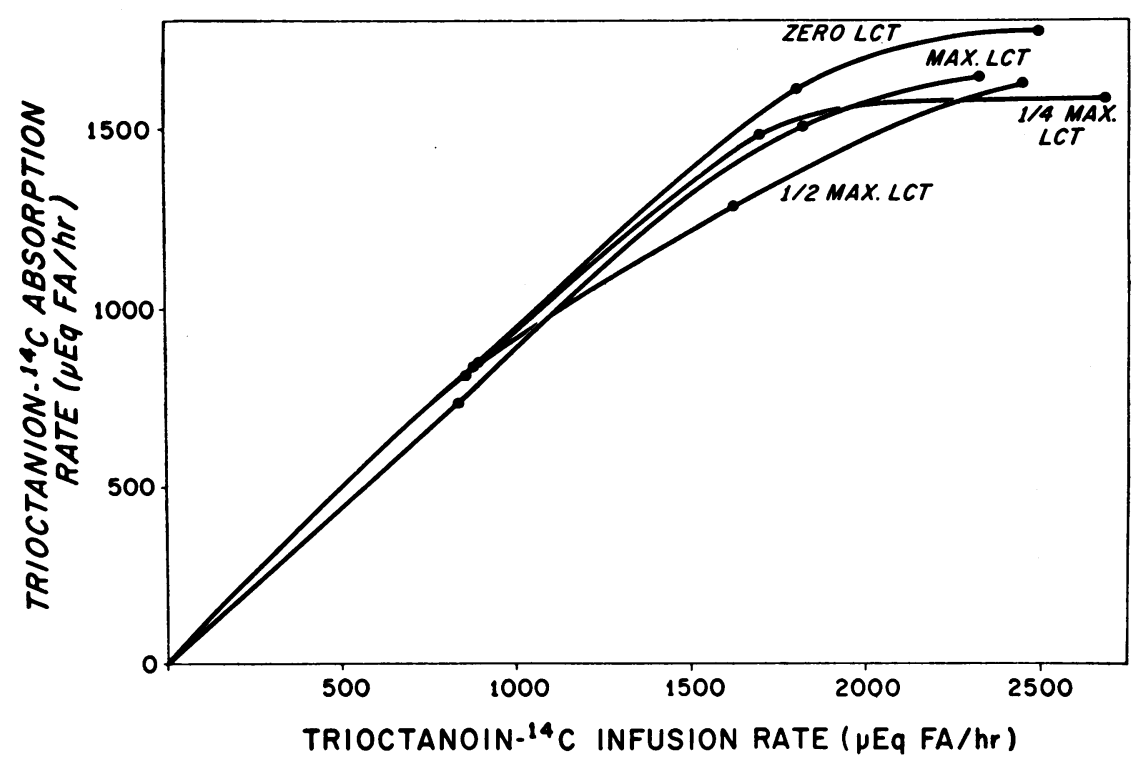

FIgURE 6 Effect of triolein-9,10- ${ }^{8} \mathrm{H}$ infusion on steady-state absorption of trioctanoin${ }_{1{ }^{14}} \mathrm{C}$. $\bullet$, mean trioctanoin absorption rates. Same animals as in Fig. 2. 


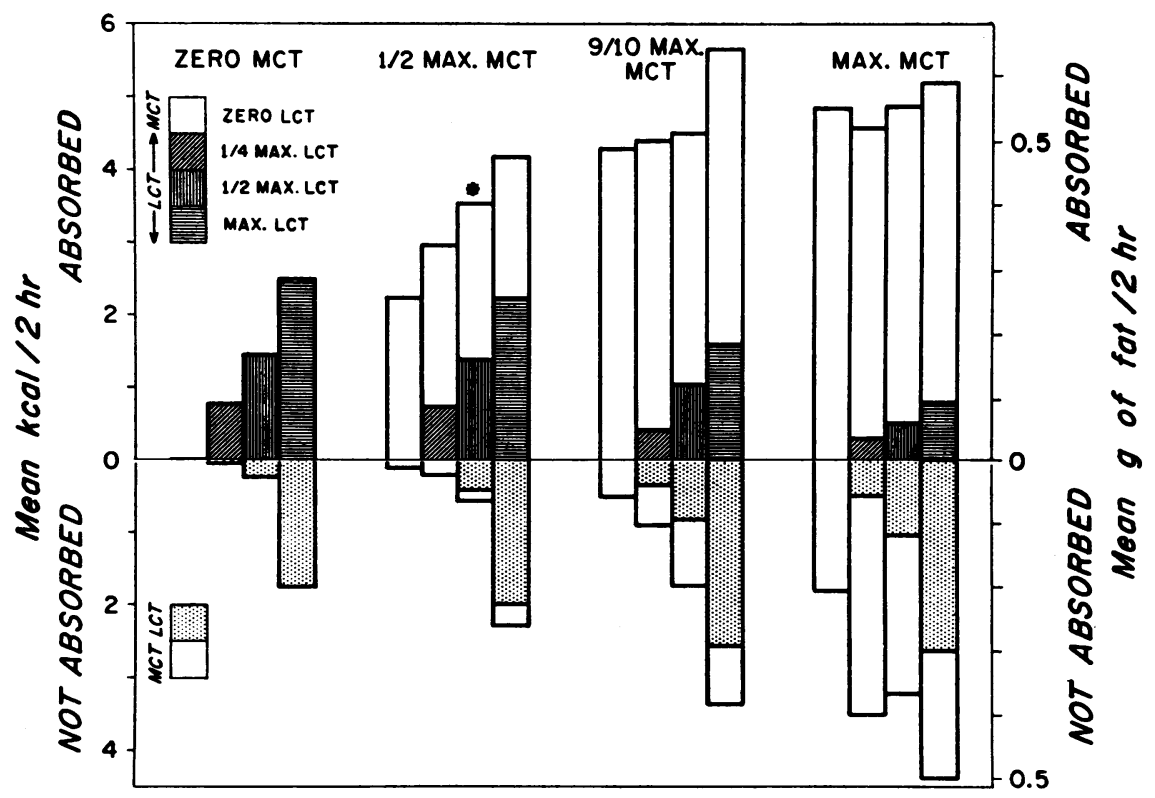

Figure 7 Total lipid absorbed and not absorbed during intraduodenal infusion of mixed triolein and trioctanoin emulsions in rats.

* Optimum dietary mixture of long- and medium-chain triglyceries. Absorption coefficient $90 \%$, caloric intake $70 \%$ of maximal.

each experimental group of animals. It is apparent that the total lipid absorbed in $2 \mathrm{hr}$ from mixed infusions also reached a maximum and that the lipid remaining unabsorbed in the lumen increased progressively with increasing total fat infusion. Maximum caloric intake was achieved when the highest levels of both LCT and MCT were infused but most of the long-chain fat then was not absorbed. However, when triolein and trioctanoin infusion rates were both half maximal (see* Fig. 7), total fat absorption reached approximately $70 \%$ of the maximum calories absorbed during the highest infusion rates of both triglycerides. With this optimum mixture, about one-third of the calories were derived from LCT and only about $10 \%$ of the total fat infused remained unabsorbed. The dosage which gave optimum absorption of this lipid mixture in rats was therefore about $16 \mathrm{kcal} / \mathrm{Kg}$ per $2 \mathrm{hr}$ administered in a ratio of about $3 \mathrm{~g} \mathrm{LCT:} 4 \mathrm{~g} \mathrm{MCT}$. Increases in trioctanoin infusion beyond this level resulted in little further caloric benefit to the animals and, in addition, less triolein was absorbed.

\section{DISCUSSION}

Absorption of triolein. The reactions that normally control the absorption of long-chain triglycerides have been extensively studied, yet the rate-limiting step in the over-all sequence has not been established. Under pathological conditions, however, several rate-controlling steps have been demonstrated. For example, in the ab- sence of luminal pancreatic lipase there is a reduction in over-all absorption and triglyceride lipolysis becomes rate limiting (14). When intraluminal bile salt concentration is decreased or luminal $\mathrm{pH}$ is low, transfer of fatty acid into the aqueous phase is reduced (15). The present studies have explored the effects of the simultaneous controlled delivery of two differing triglycerides to the intestinal lumen on the maximal absorption rate of each. Triolein and trioctanoin were chosen since, once absorbed into the intestinal mucosal cell, the medium-chain fatty acid is rapidly transported into the portal vein and thus was not expected to compete with any of the intracellular reactions necessary for the ultimate incorporation of the long-chain fatty acid into chylomicrons. ${ }^{1}$

Previous studies, reconfirmed in the present investigation, have demonstrated that during intraduodenal infusion of several emulsified triglycerides a steady state of absorption is achieved within a very short time (2). If in a steady-state system diffusion is the sole mechanism for the movement of a given substance between two adjacent compartments separated by a completely permeable membrane, the rate of net transfer will be

${ }^{1}$ A very recent study by Robins, Small, and Donaldson (16) has demonstrated that some esterification of long-chain fatty acid may occur in the mucosal brush border membrane although the quantitative importance of this reaction is not yet clear. Conceivably, when octanoic acid passes through the membrane at high rates, oleic acid esterification may be inhibited in this region of the cell. 
linearly related to the difference between the activities of the diffusing substances in the two compartments. Recent measurements of uptake of long-chain fatty acids by rat gut segments in vitro established a $Q_{10}$ of about 1.5 which is consistent with a passive diffusion mechanism (17). Preliminary data obtained in our laboratory from studies using everted slices and sacs of rat jejunum incubated at $0^{\circ}$ and $28^{\circ} \mathrm{C}$ with buffered media containing $10 \mathrm{~mm}$ bile salt and oleic acid at various concentrations were similarly consistent with an energyindependent permeation of intestinal cell membranes by long-chain fatty acid in vitro. However, one study using everted sacs of small intestine (18) has suggested that mucosal uptake of short-chain fatty acids is not wholly explainable by passive diffusion. Another in vitro study (19) has suggested that a $\mathrm{Na}^{+}$-dependent, energy-independent system is involved in the uptake of oleic acid, a long-chain fatty acid, and of nonoolein. Hogben (20) has calculated that diffusion is sufficient to account for the rate of intestinal fatty acid absorption in vivo under normal conditions of gastric emptying. However, in the present in vivo experiments in which triolein alone was infused at high rates intraduodenally in unanesthetized rats, the rate of transport of oleic acid into the mucosal cell did not increase linearly with increasing aqueous oleic acid concentration but there was evidence of transport saturation (see Fig. 5). This observation could imply that the luminal aqueous monomeric oleic acid phase in equilibrium with micelles was saturated at high triolein infusion rates and that the diffusion of oleic acid monomers into the mucosal cell was thereby limited. The curvilinear relation obtained would then also suggest that uptake of whole micelles was not a major mechanism in triolein absorption under these conditions. On the other hand, the results could equally suggest saturation of some active process involved in fatty acid uptake by mucosal cells.

When trioctanoin was rapidly infused, the luminal contents were markedly acidified due to the presence of large amounts of unabsorbed octanoic acid whose $\mathrm{pKa}$ in water is about 4.8. Since low $\mathrm{pH}$ favors the partition of fatty acid into the oil phase by increasing the ratio of unionized to ionized fatty acid in the aqueous phase (21), the aqueous oleic acid concentration was reduced when trioctanoin was infused with triolein. However, simultaneous infusion of trioctanoin lowered the triolein absorption rate considerably more than would have been expected from the observed reduction in concentration of either unionized or total oleic acid in the luminal aqueous phase. Several explanations may be proposed. The activity of long-chain fatty acid monomers may have been less in the presence of octanoic acid. The intramucosal $\mathrm{pH}$ may have been lowered during rapid absorption of MCT, increasing the proportion of unionized oleic acid intracellularly and decreasing the concentration gradient between lumen and mucosal cells. In such a situation high levels of MCT infusion might reduce LCT absorption by decreasing passive diffusion of unionized oleic acid into the mucosal cell. Finally, mediumand long-chain fatty acids may have competed for some restricted pathway.

It has been suggested that octanoate can inhibit palmitic acid thiol ester formation in microsomal fractions of rat intestine, although no octanoic acid thiol ester is formed (22). In unpublished experiments from our laboratory, however, esterification of oleic acid was not reduced by octanoate in everted sacs of rat jejunum. It seems unlikely, therefore, that the in vivo inhibition of oleic acid uptake by octanoate resulted from interference with oleic acid thiol ester formation. Moreover, a study by Hyun, Vahouny, and Treadwell in unanesthetized rats (23) clearly showed that $45 \%$ inhibition of mucosal esterification of oleic acid by 2 -ethyl- $n$-caproic acid produced no decrease in oleic acid uptake and that there was no long-chain fatty acid accumulation within the mucosa. Their results implied that in the intact animal intracellular fatty acid concentration does not increase even when esterification is inhibited since long chain fatty acid is then removed by the portal route. Consequently, it is doubtful whether an increased intramucosal oleic acid concentration during trioctanoin absorption could have caused the reduction of LCT absorption by MCT observed in vivo.

In summary, the present study demonstrates that high levels of trioctanoin infusion with triolein intraduodenally in intact animals can suppress absorption of the long-chain lipid. It has not been possible to isolate the mechanism for this inhibition. A change in the chemical activity of oleic acid in the aqueous monomer phase from which mucosal uptake probably occurs may be responsible. Alternatively, octanoate may have competed with oleic acid for some membrane component involved in the mucosal uptake of fatty acid. The lack of inhibition of trioctanoin absorption by triolein in the present experiments does not invalidate the suggestion that fatty acid uptake may involve competition at a common site. For example, one group of animals (maximal LCT, 9/10 maximal MCT) received about $4000 \mu \mathrm{Eq}$ of octanoate and about $1600 \mu \mathrm{Eq}$ of oleate and absorbed about 3000 and $600 \mu \mathrm{Eq}$ of medium and long-chain fatty acid respectively (see Table II). That is, triolein absorption was reduced by about $300 \mu \mathrm{Eq}$ of fatty acid while $3000 \mu \mathrm{Eq}$ of octanoate were absorbed, a ratio of octanoate to oleate traversing the mucosal membrane of about 10:1. Clearly, the proportions of LCT to MCT necessary to detect any inhibition of trioctanoin absorption were not reached in the present experiments. 
Clinical implications of MCT as a caloric supplement. Medium-chain triglyceride preparations are now frequently used as a caloric supplement in malabsorptive states due to various causes. The present data suggest that administration of very large quantities of MCT preparations could interfere with the absorption of dietary long-chain triglycerides and increase fecal losses of long-chain fatty acids. Increased steatorrhea has been observed during supplemental MCT administration in patients following intestinal resections (24). The increased fecal losses of lauric acid in patients with celiac disease when a triglyceride extensively interesterified with octanoic acid was administered with coconut oil (25) may also be explained by the present results. The data from rats nevertheless suggest that in patients with reduced intestinal absorptive capacity who receive $\mathrm{MCT}$ as a caloric supplement the dietary fat intake normally tolerated might be approximately doubled with MCT formula with no increase in steatorrhea of long-chain fatty acids. The optimum proportions of MCT and LCT and the total amounts fed to patients with fat malabsorption should, however, be tailored individually to suit the clinical needs of the patient.

\section{ACKNOWLEDGMENTS}

The technical assistance of Miss Michele Moore is gratefully acknowledged. Dr. A. K. Said carried out some of the initial experiments in partial fulfillment of the requirements for the degree of Master of Sciences from the Institute of Nutritional Sciences, Columbia University. We also thank Dr. W. C. Clark of the New York State Psychiatric Institute for assistance with the statistical analyses, and Drs. D. M. Small and A. F. Hofmann for constructive criticism during preparation of the manuscript.

This work was supported by grants from the National Institutes of Health HE-10055 and AM-08107.

\section{REFERENCES}

1. Clark, S. Bennett, and P. R. Holt. 1968. Competition for intestinal absorption of triglycerides. Gastroenterology. 54: 1227. (Abstr.)

2. Bennett, S., and W. J. Simmonds. 1962. Absorptive capacity and intestinal motility in unanaesthetised rats during intraduodenal infusion of fat. Quart. J. Exp. Physiol. $47: 32$.

3. Bennett, S. 1964. Intestinal absorptive capacity and site of absorption of fat under steady state conditions in the unanaesthetised rat. Quart. J. Exp. Physiol. 49: 210.

4. Desnuelle, P., and P. Savary. 1963. Specificities of lipases. J. Lipid Res. 4: 369.

5. Hofmann, A. F., and B. Borgström. 1964. The intraluminal phase of fat digestion in man: The lipid content of the micellar and oil phases of intestinal content obtained during fat digestion and absorption. J. Clin. Invest. 43: 247.
6. Clark, S. Bennett and P. R. Holt. 1968. Rate-limiting steps in steady state intestinal absorption of trioctanoin$1{ }^{14}$ C. J. Clin. Invest. $47: 612$.

7. Fernandes, J., J. H. van de Kamer, and H. A. Weijers. 1955. Absorption of fats studied in a child with chylothorax. J. Clin. Invest. 34: 1026.

8. Thomas, A. E., III, J. E. Scharoun, and H. Ralston. 1965. Quantitative estimation of isomeric monoglycerides by thin layer chromatography. J. Amer. Oil Chem. Soc. 42: 789.

9. Bray, G. A. 1960. A simple and efficient scintillator for counting aqueous solutions in a liquid scintillation counter. Anal. Biochem. 1: 279.

10. Bush, E. T. 1964. Liquid scintillation counting of doublylabeled samples. Anal. Chem. 36: 1082.

11. Hofmann, A. F., and B. Borgström. 1963. Hydrolysis of long-chain monoglycerides in micellar solution by pancreatic lipase. Biochim. Biophys. Acta. 70: 317.

12. Winer, B. J. 1962. Statistical Principles in Experimental Design. McGraw-Hill Book Company, New York. 298.

13. Mattson, F. H., and R. A. Volpenhein. 1964. The digestion and absorption of triglycerides. J. Biol. Chem. 239: 2772.

14. Anderson, C. M. 1966. Intestinal malabsorption in childhood. Arch. Dis. Child. 41 : 571.

15. Hofmann, A. F. 1966. A physicochemical approach to the intraluminal phase of fat absorption. Gastroenterology. 50: 56.

16. Robins, S. J., D. M. Small, and R. M. Donaldson, Jr. 1969. Triglyceride formation in intestinal microvillous membranes during fat absorption. J. Clin. Invest. 48: 69a. (Abstr.)

17. Porte, D., and C. Entenman. 1965. Fatty acid metabolism in segments of rat intestine. Amer. J. Physiol. 208: 607.

18. Barry, R. J. C., M. J. Jackson, and D. H. Smyth. 1965. Transfer of proprionate by rat small intestine in vitro. J. Physiol. 182: 150.

19. Lyon, I. 1968. Studies on transmural potentials in vitro in relation to intestinal absorption $\bar{V}$ Kinetic characteristics of lipid interactions with rat gut. Biochim. Biophys. Acta. 163: 75 .

20. Hogben, C. A. M. 1966. Fat absorption: a transport problem. Gastroenterology. 50: 51.

21. Borgström, B. 1967. Partition of lipids between emulsified oil and micellar phases of glyceride-bile salt dispersions. J. Lipid Res. 8: 598.

22. Vahouny, G. V., J. Nelson, and C. R. Treadwell. 1968. Inhibition of triglyceride synthesis in everted intestinal sacs. Proc. Soc. Exp. Biol. Med. 128: 495.

23. Hyun, S. A., G. V. Vahouny, and C. R. Treadwell. 1967. Mechanism of stimulation of cholesterol absorption by 2 -ethyl-n-caproic acid in vivo. Biochim. Biophys. Acta. $137: 306$.

24. Greenberger, N. J. 1967. Metabolic and clinical studies of medium chain triglycerides in subjects with inflammatory small bowel disease. In Medium Chain Triglycerides. J. R. Senior, editor. University of Pennsylvania Press. 145.

25. Fernandes, J., J. H. van de Kamer, and H. A. Weijers. 1961. Differences in absorption of the various fatty acids studied in children with steatorrhea. J. Clin. Invest. 41: 488. 